\title{
Higher dose rate Gamma Knife radiosurgery may provide earlier and longer-lasting pain relief for patients with trigeminal neuralgia
}

\author{
John Y. K. Lee, MD, MSCE, ${ }^{1}$ Sukhmeet Sandhu, BA, ${ }^{1}$ Denise Miller, BSN, ${ }^{1}$ Timothy Solberg, PhD, ${ }^{2}$ \\ Jay F. Dorsey, $\mathrm{MD}, \mathrm{PhD},{ }^{2}$ and Michelle Alonso-Basanta, $\mathrm{MD}, \mathrm{PhD}^{2}$
}

Departments of ${ }^{1}$ Neurosurgery and ${ }^{2}$ Radiation Oncology, University of Pennsylvania, Philadelphia, Pennsylvania

\begin{abstract}
OBJECT Gamma Knife radiosurgery (GKRS) utilizes cobalt-60 as its radiation source, and thus dose rate varies as the fixed source decays over its half-life of approximately 5.26 years. This natural decay results in increasing treatment times when delivering the same cumulative dose. It is also possible, however, that the biological effective dose may change based on this dose rate even if the total dose is kept constant. Because patients are generally treated in a uniform manner, radiosurgery for trigeminal neuralgia (TN) represents a clinical model whereby biological efficacy can be tested. The authors hypothesized that higher dose rates would result in earlier and more complete pain relief but only if measured with a sensitive pain assessment tool.
\end{abstract}

METHODS One hundred thirty-three patients were treated with the Gamma Knife Model 4C unit at a single center by a single neurosurgeon during a single cobalt life cycle from January 2006 to May 2012. All patients were treated with 80 Gy with a single 4-mm isocenter without blocking. Using an output factor of 0.87 , dose rates ranged from 1.28 to 2.95 Gy/min. The Brief Pain Inventory (BPI)-Facial was administered before the procedure and at the first follow-up office visit 1 month from the procedure (mean 1.3 months). Phone calls were made to evaluate patients after their procedures as part of a retrospective study. Univariate and multivariate linear regression was performed on several independent variables, including sex, age in deciles, diagnosis, follow-up duration, prior surgery, and dose rate.

RESULTS In the short-term analysis (mean 1.3 months), patients' self-reported pain intensity at its worst was significantly correlated with dose rate on multivariate analysis $(p=0.028)$. Similarly, patients' self-reported interference with activities of daily living was closely correlated with dose rate on multivariate analysis $(p=0.067)$. A 1 Gy/min decrease in dose rate resulted in a $17 \%$ decrease in pain intensity at its worst and a $22 \%$ decrease in pain interference with activities of daily living. In longer-term follow-up (mean 1.9 years), GKRS with higher dose rates (> $2.0 \mathrm{~Gy} / \mathrm{min} ; p=0.007)$ and older age in deciles $(p=0.012)$ were associated with a lower likelihood of recurrence of pain.

DISCUSSION Prior studies investigating the role of dose rate in Gamma Knife radiosurgical ablation for TN have not used validated outcome tools to measure pain preoperatively. Consequently, differences in pain outcomes have been difficult to measure. By administering pain scales both preoperatively as well as postoperatively, the authors have identified statistically significant differences in pain intensity and pain interference with activities of daily living when comparing higher versus lower dose rates. Radiosurgery with a higher dose rate results in more pain relief at the early follow-up evaluation, and it may result in a lower recurrence rate at later follow-up.

http://thejns.org/doi/abs/10.3171/2014.12.JNS142013

KEY WORDS trigeminal neuralgia; Gamma Knife radiosurgery; dose rate; Brief Pain Inventory-Facial; stereotactic radiosurgery; pain

$\mathrm{G}$ AMMA Knife radiosurgery (GKRS) is frequently used to treat patients with trigeminal neuralgia (TN) ${ }^{3,8,9,17}$ Cobalt-60 is the radiation source for the Leksell Gamma Knife unit, and dose rates vary because the fixed sources have a half-life of 5.26 years. As the dose rate decreases with time, the treatment time increases. The biological effect of the lower dose rate and increased treatment time may lead to significant differences in clinical outcomes. In contrast, linear accelerator radiosurgery does not generally have varying dose rates on the same machine, because dose rate can be held constant in different patients.

ABBREVIATIONS AED = antiepileptic drug; BNI = Barrow Neurological Institute; $\mathrm{BPI}=$ Brief Pain Inventory; GKRS = Gamma Knife radiosurgery; TN = trigeminal neuralgia; TN1 = TN Type 1; TN2 = Type 2 .

SUBMITTED August 30, 2014. ACCEPTED December 30, 2014

INCLUDE WHEN CITING Published online August 7, 2015; DOI: 10.3171/2014.12.JNS142013.

DISCLOSURE The authors report no conflict of interest concerning the materials or methods used in this study or the findings specified in this paper. 
Prior studies of GKRS for TN have shown differences in outcomes associated with total dose delivered to the trigeminal nerve, ${ }^{6,14,19}$ but studies have not identified any significant differences as a result of the rate at which the dose was delivered. The outcome measures used in those studies have been particularly crude, and no study has measured pain prior to GKRS intervention. Zakrezewska et al.'s review suggests that only a fraction of outcome studies in TN have actually measured pain prior to intervention..$^{13,23}$ Most studies have assumed that pain is "severe" and has affected quality of life, without attempting to measure either of these factors. The senior author (J.Y.K.L.) published the validation study of the Brief Pain Inventory (BPI)-Facial outcome tool in 2010.5,11 This outcome tool can be used to measure pain before and after GKRS to measure change in pain in a quantitative manner, thus providing greater insight to the effects of various patient- and treatment-related parameters. We hypothesized that administration of this tool prior to GKRS may provide a more sensitive test of efficacy, allowing us to study the effect of dose rate in a more systematic manner.

\section{Methods \\ Study Population}

This study was a retrospective review of all patients treated by a single neurosurgeon (J.Y.K.L.) at a single hospital (Pennsylvania Hospital at the University of Pennsylvania) from 2006 to 2012, approved by the University of Pennsylvania Institutional Review Board. All patients completed the BPI-Facial outcome tool at the first clinic visit as well as at subsequent clinic visits, including postoperatively after GKRS. Paper forms were completed by the patients at their own pace without physician supervision. Also, patients were not given their prior BPI-Facial forms to reference when they completed the postoperative BPIFacial. Hence, all results represent blinded, uninfluenced, patient-oriented outcomes. These forms were stored in the paper chart until 2012, at which time data were collected and entered into a computerized relational database (Access, Microsoft Corp.). Data were analyzed using STATA statistical software (version 10, StataCorp LP).

\section{Gamma Knife Treatment Parameters}

The University of Pennsylvania Gamma Knife unit at Pennsylvania Hospital (Model 4C, Elekta AB) was installed in November 2005 and patients with TN were treated from January 2006 until May 2012. After May 2012, the 4C unit was upgraded to a Leksell Gamma Knife Perfexion unit. All patients were treated by the senior author (J.Y.K.L.) and almost all patients were prescribed 80 Gy to the $100 \%$ maximum dose with a 4-mm collimator. No blocks were used in any patient. An output factor of 0.87 was used throughout the period..$^{20}$ All patients were advised to remain on their same dose of medications until their first postoperative visit, at which time they were advised as to how to taper their medications.

\section{Data Collection}

Patient data were collected before GKRS, at the patients' first postprocedure visit scheduled approximately 1 month after the GKRS procedure, and during the telephone questionnaire in 2012. Details of the data analysis have been presented elsewhere (Lee et al. 2010), ${ }^{11}$ but in brief, postoperative raw scores were subtracted from preoperative raw scores, divided by the preoperative raw score, and multiplied by 100 to obtain a percentage change. The 7 interference items of the general activities of daily living were averaged together, and the 7 interference items of the facial activities of daily living were averaged together.

\section{Statistical Analysis}

Short-term analysis of the 1-month postprocedure data was performed using STATA 10. The BPI-Facial provides quantitative comparisons between the preoperative baseline score and the postoperative score at 1 month. The percentage change in the preoperative and postoperative score was used as the outcome variable. Linear regression was used to compare predictor variables. Dose rate was tested as a continuous variable, and sex, age in deciles, follow-up duration, diagnosis (Burchiel TN Type 1 [TN1] vs Burchiel TN2, and any TN diagnosis versus "other diagnosis"), and prior surgery for TN (yes or no) were tested as univariate variables. Variables with p values less than 0.3 were entered into the multivariate linear regression model.

For longer-term outcomes, telephone questionnaires were initiated in 2012, and they followed a prescribed routine, including administration of the BPI-Facial. Patients who could not be contacted were considered censored at their last available follow-up evaluation, which was usually their 1-month posttreatment office visit. Any pain recurrence was defined as "any pain" regardless of whether the patient described it as "sharp, shooting" or "constant, burning." In addition, a medication list was obtained from the patient, but no attempt was made to discern the cause for taking medications, such as radiculopathy pain versus TN pain. Cox regression was used to test predictor variables. Univariate predictors included the following: dose rate (high vs low), sex, age in deciles, follow-up duration, diagnosis (Burchiel TN1 vs Burchiel TN2, and any TN diagnosis vs "other diagnosis"), and prior surgery for TN (yes or no). Variables with a $\mathrm{p}$ value less than 0.3 were entered into the multivariate model.

\section{Results}

A total of 133 patients were treated during the time period (Table 1). Of these patients, $57 \%$ were female, and the mean age was 68 years (range 35-95 years). Right-sided facial pain was observed in 55\%. Eighty-four percent of the total study population was treated for a diagnosis of either TN1 ( $>50 \%$ sharp, shooting pain) or TN2 $(<50 \%$ sharp, shooting pain), using the Burchiel classification scheme. ${ }^{4}$ An additional $10 \%$ were treated for a diagnosis of multiple sclerosis-related TN. The remaining $6 \%$ of patients were treated for a diagnosis of atypical facial pain or other diagnosis. Almost one-quarter of the patients $(24 \%)$ had previously been treated with a neurosurgical procedure for their TN.

Ninety-seven percent of patients were prescribed the same dose, 80 Gy to the $100 \%$ maximum. Only 4 patients were treated with a dose lower than $80 \mathrm{~Gy}$, and these were all retreatments $(50,60,70$, and 75 Gy each). The mean 
TABLE 1. Patient characteristics

\begin{tabular}{lc}
\hline \multicolumn{1}{c}{ Characteristic } & Value \\
\hline No. of patients & 133 \\
\hline Female (\%) & 57 \\
\hline Rt-sided pain (\%) & 55 \\
\hline Follow-up duration in mos (range) & $1.3(0-7.9)$ \\
\hline Diagnosis (\%) & 66 \\
\hline Burchiel TN1 & 18 \\
\hline Burchiel TN2 & 10 \\
\hline Multiple sclerosis & 6 \\
\hline Atypical facial pain \& other & 10 \\
\hline Age in deciles (\%) & 16 \\
\hline$<50$ yrs & 25 \\
\hline $50-60$ yrs & 33 \\
\hline $60-70$ yrs & 17 \\
\hline $70-80$ yrs & $68(35-95)$ \\
\hline$>80$ yrs & $2.04(1.28-2.95)$ \\
\hline Mean age in yrs (range) & \\
\hline Mean GKRS dose rate in Gy/min (range) & 12 \\
\hline Maximum dose in Gy & 7 \\
\hline Prior procedures (\%) & $50-80)$ \\
\hline Microvascular decompression & \\
\hline Percutaneous rhizotomy & \\
\hline GKRS & \\
\hline
\end{tabular}

GKRS dose rate was $2.04 \mathrm{~Gy} / \mathrm{min}$, and the range varied from 1.28 to $2.95 \mathrm{~Gy} / \mathrm{min}$.

\section{Short-Term Results}

Patients were evaluated in the office an average of 1.3 months after the GKRS procedure. Patients were not asked to taper medications until this early posttreatment visit, and thus most patients remained on the same medications at the time of data collection. Even at this early time point, the majority of patients reported improvement after their GKRS procedure. Fifty-nine percent of patients rated themselves as "very much improved" or "much improved" using a 7-point Global Impression of Change ${ }^{11}$ ranging from "very much improved" to "very much worse." Statistically, patients as a group demonstrated significant improvement in all dimensions of pain as measured by the BPI-Facial (Table 2). For example, mean preoperative pain, at its worst, was 7.9 , versus 4.4 at 1 month after GKRS (Fig. 1). Similarly, the mean preop- erative BPI-Facial score for the averaged interference with general activities items was 6.7 before GKRS and 2.6 at 1 month afterward (Table 2).

Univariate and multivariate linear regression was used to build a model to predict the percentage change in pain intensity (worst and average), interference with general activities of daily living, and interference with facial-specific activities of daily living (Table 3). At 1-month follow-up, for pain at its worst, the strongest predictor of percentage pain relief was dose rate $(\mathrm{p}=0.028)$. The coefficient was $17 \%$, and hence a $1 \mathrm{~Gy} / \mathrm{min}$ decrease in dose rate resulted in a $17 \%$ less change in pain intensity at its worst between the preoperative and postoperative score (Fig. 2). Similarly, at 1-month follow-up, for interference of general activities of daily living, the strongest predictor of percentage pain relief was dose rate $(\mathrm{p}=0.067)$. The coefficient was $22 \%$, and hence a $1 \mathrm{~Gy} / \mathrm{min}$ decrease in dose rate resulted in a $22 \%$ less change in the averaged interference of general activities of daily living between the preoperative and postoperative score. At the earliest time point (mean 1.3 months after GKRS), using multivariate analysis, no variable was a significant predictor of pain intensity on average or interference of facial-specific activities of daily living.

\section{Long-Term Follow-Up}

To study long-term outcomes, patients were called an average of 1.9 years after their GKRS procedure (range 0.2-6.7 years). Ninety-nine of the total 133 patients consented to participation in the long-term follow-up study and/or were able to be contacted via telephone. The remaining 34 patients were considered censored at their 1-month follow-up visit.

Forty-one patients reported recurrence of "any facial pain" at some time point after their procedure, resulting in a crude pain recurrence rate of $31 \%$ (41/133). KaplanMeier survival methods were used to calculate "time to event," in this case "time to any facial pain recurrence." The median duration of freedom from pain recurrence was 4.1 years (Fig. 3).

Cox regression was used to calculate univariate and multivariate predictors of pain recurrence. In multivariate analysis, 2 variables were statistically significant predictors of pain recurrence: age in deciles $(p=0.012)$, and dose rate (high vs low, $\mathrm{p}=0.007$; Table 4 ). Figure 4 demonstrates the percentage of failure according to each age decade. Younger patients were more likely to experience pain recurrence. Also, because the median dose rate was calculated to be $2.0 \mathrm{~Gy} / \mathrm{min}$, patients were grouped into high dose rate $(>2.0 \mathrm{~Gy} / \mathrm{min})$ and low dose rate $(<2.0 \mathrm{~Gy} / \mathrm{min})$.

TABLE 2. Preoperative and postoperative BPI-Facial scores

\begin{tabular}{lccccc}
\hline & & \multicolumn{4}{c}{ Post-Procedure } \\
\cline { 3 - 6 } Variable & Pre-Procedure Score & 1-month Score & $p$ Value & Long-Term Score & $p$ Value \\
\hline Pain at its worst & 7.9 & 4.4 & 0.0001 & 2.4 & 0.0001 \\
\hline Pain on average & 6.0 & 3.0 & 0.0001 & 1.4 & 0.0001 \\
\hline BPI-General interference items (mean) & 6.7 & 2.6 & 0.0001 & 1.1 & 0.0001 \\
\hline BPI-Facial interference items (mean) & 5.6 & 2.3 & 0.0001 & 1.3 & 0.0001 \\
\hline$\%$ of patients on AED pain medications & 90 & 85 & & 43 & \\
\hline
\end{tabular}




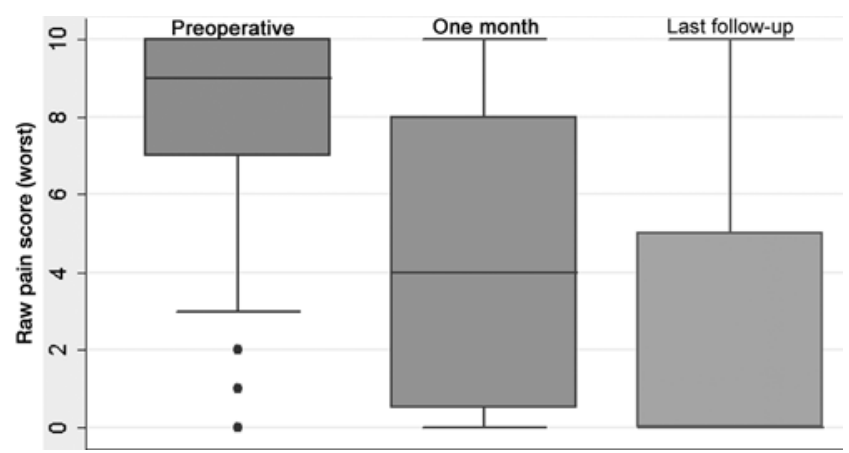

FIG. 1. Box-and-whisker plot with medians, quartiles, and spread of pain intensity (worst) scores at 3 time points: preoperatively, 1 month after the procedure, and last follow-up evaluation. Circles represent additional patients outside the quartiles

Patients treated with a higher dose rate were more likely to be pain-free at the last follow-up time period as compared with patients treated with a lower dose rate (Fig. 5).

As a check of internal consistency of the long-term outcomes, we compared the BPI-Facial scores for the patients who had pain recurrence as well as those who did not (Table 5). Patients who described themselves as having had a recurrence reported $59 \%$ change in pain at its worst between their preoperative and postoperative score. In contrast, patients who described themselves as not having had a recurrence, reported $78 \%$ change in pain at its worst between their preoperative and postoperative score $(\mathrm{p}=0.054)$. Interestingly, even though patients reported themselves as having recurrent pain, they still demonstrated improvement as compared with their baseline scores. This may be related to the fact that they were not shown their original pain scores when they were asked over the telephone what their pain level was at present.

As another level of internal consistency of long-term outcomes, we compared the likelihood of taking antiepileptic drugs (AEDs) before and after GKRS. Every patient had tried AEDs prior to GKRS. At the time of the procedure, $90 \%$ of patients were actively taking AEDs. At last follow-up, $43 \%$ of all patients were taking AEDs. However, patients who were considered to have had a recurrence of pain were almost 3 times more likely to be taking AEDs as compared with patients who did not have pain

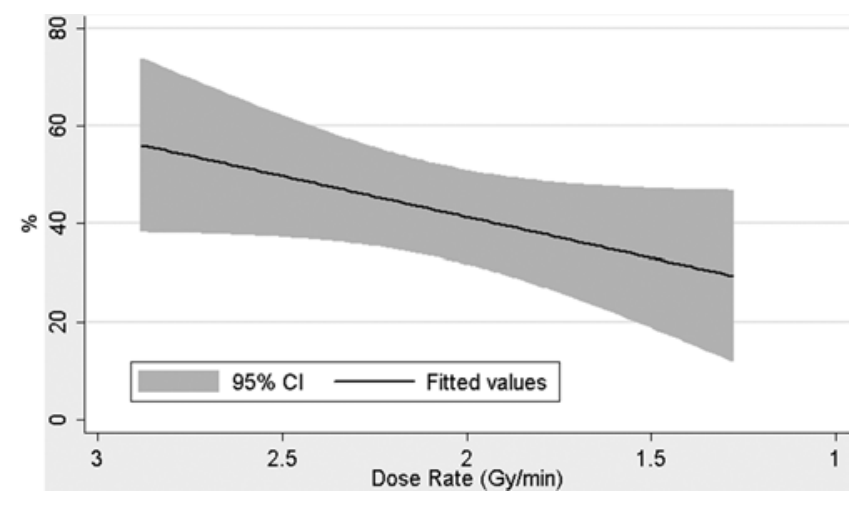

FIG. 2. The linear regression model demonstrating percentage change in pain intensity (worst) versus dose rate (Gy/min).

recurrence (63\% vs 26\%, respectively; $\mathrm{p}<0.05$, Fisher's exact test).

Of note, $10 \%$ of patients reported new numbness or change in the distribution of preexisting numbness at the last follow-up evaluation. Figure 6 demonstrates the time to numbness for patients who had a recurrence of pain. This was not a statistically significant predictor of outcome at the last follow-up evaluation.

\section{Discussion}

Gamma Knife radiosurgery is one of several treatment modalities for patients with idiopathic TN. ${ }^{10,12}$ Approximately $75 \%$ to $80 \%$ of patients experience pain relief, and the median pain-free period after the procedure is approximately 3 to 5 years..$^{13,15,16}$ Predictors of pain relief in patients undergoing radiosurgery have included patient factors such as young age, absence of prior procedures, ${ }^{8}$ shorter pain duration before the procedure, ${ }^{10}$ and development of facial numbness. ${ }^{8,14}$ Some features of the GKRS procedure itself have been identified as predictors of pain relief, such as higher total dose ${ }^{16,19}$ and greater total volume of nerve irradiated. ${ }^{6,19}$ Only 2 prior studies have investigated the role of dose rate in TN outcomes, and they found no correlation. ${ }^{1,2}$ We hypothesized that one possible limitation of these prior studies was the lack of a sensitive measurement tool for TN pain, and thus subtle differences between patients and within patients may be lost by

TABLE 3. Predictors of short-term pain relief based on percentage change*

\begin{tabular}{|c|c|c|c|c|c|c|c|c|}
\hline \multirow[b]{2}{*}{ Predictor } & \multicolumn{2}{|c|}{$\begin{array}{l}\text { Pain Intensity } \\
\text { Worst }\end{array}$} & \multicolumn{2}{|c|}{$\begin{array}{l}\text { Pain Intensity } \\
\text { Average }\end{array}$} & \multicolumn{2}{|c|}{$\begin{array}{c}\text { BPI-General } \\
\text { Interference Items }\end{array}$} & \multicolumn{2}{|c|}{$\begin{array}{c}\text { BPI-Facial } \\
\text { Interference Items }\end{array}$} \\
\hline & Uni. & Multi. & Uni. & Multi. & Uni. & Multi. & Uni. & Multi. \\
\hline Dose rate & 0.076 & 0.028 & 0.5212 & & 0.0533 & 0.067 & 0.3261 & \\
\hline Sex & 0.8105 & & 0.666 & & 0.4104 & & 0.1091 & \\
\hline Age in deciles & 0.9657 & & 0.9602 & & 0.8248 & & 0.8755 & \\
\hline Follow-up duration (mos) & 0.7489 & & 0.8359 & & 0.2714 & 0.351 & 0.2861 & \\
\hline Diagnosis (TN1 vs TN2) & 0.832 & & 0.7698 & & 0.8527 & & 0.5876 & \\
\hline Diagnosis (Any TN vs other) & 0.1099 & 0.167 & 0.2355 & 0.223 & 0.5498 & & 0.3551 & \\
\hline Prior surgery for TN & 0.2302 & 0.211 & 0.1082 & 0.162 & 0.7293 & & 0.5732 & \\
\hline Maximum dose & 0.2915 & & 0.4106 & & 0.4167 & & 0.5107 & \\
\hline
\end{tabular}

Multi. = multivariate analysis; Uni. = univariate analysis.

* All values given in table are $p$ values. 


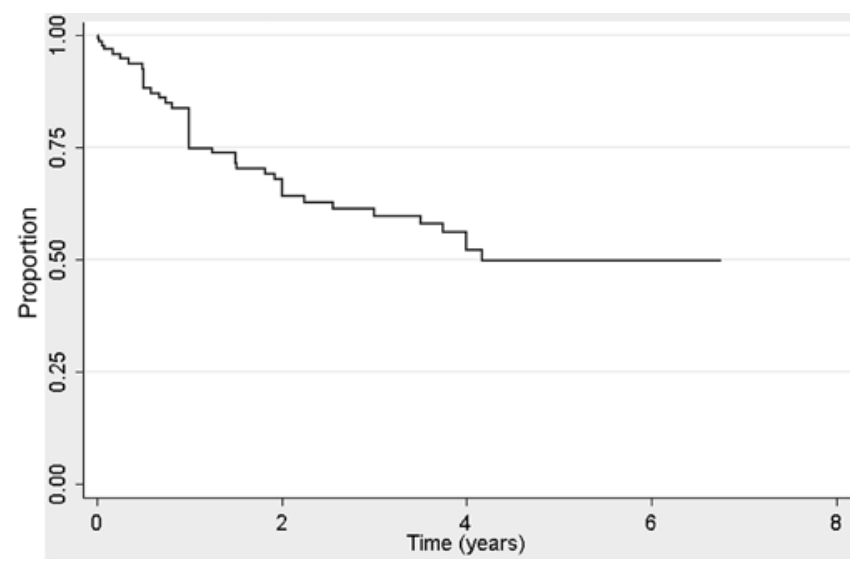

FIG. 3. Kaplan-Meier curve estimating the time to any pain recurrence after GKRS.

not measuring pain before and after the procedure. In this context, we hypothesized that the BPI-Facial (Appendix) may provide insight by providing a numeric measure of pain intensity and pain interference with activities of daily living. ${ }^{11}$

Traditional studies in TN have used the Barrow Neurological Institute (BNI) pain outcome scale. The BNI is a composite scale with psychometric properties that has not been validated. The scale classifies pain into subjective categories: none, occasional, some, severe. In addition, this composite scale combines use of pain medications into its scale and grades medication use into 3 categories: no medications, and some medications with or without adequate pain relief. Although this scale allows for 12 discrete permutations of outcomes, only 5 or sometimes 6 of the permutations are used for grading. In addition, changes from baseline are not used with the BNI scale. Hence, the senior author did not consider this scale to be appropriate for short-term analysis. Another alternative method of measuring pain outcomes used in the TN literature is survival analysis, which is a method of studying the "time to event." Because 1-month follow-up was not considered to be long enough for the event of interest (pain recurrence), an alternative and actually more traditional method of pain outcome analysis was used. Pain was measured before and after intervention using a multidimensional scale, the BPI-Facial.

In our study we scored pain on a scale of $0-10$ before and after intervention. Patients rated their facial pain at its worst as 7.9 and then 4.4 at their 1-month postprocedure visit (Table 2). Thus, because the BPI-Facial provides a numerical outcome measure, we then performed a linear regression to predict percentage change. This powerful technique demonstrated that dose rate was the most significant predictor of pain relief $(\mathrm{p}=0.028)$ on multivariate regression (Table 3). This analysis was repeated for pain interference with activities of daily living, and dose rate was once again the most powerful predictor of pain relief $(p=0.067)$. Thus, patients treated with a dose rate $>$ $2 \mathrm{~Gy} / \mathrm{min}$ experienced more dramatic pain relief at their 1-month follow-up visit.

Prior studies have examined the effect of dose rate on TN outcomes. Arai et al. from the University of Pittsburgh studied 165 patients treated with a maximum dose of 80
TABLE 4. Predictors of long-term pain relief*

\begin{tabular}{lcc}
\hline \multicolumn{1}{c}{ Predictor } & Univariate & Multivariate \\
\hline Dose rate (high/low) & 0.0008 & 0.007 \\
\hline Sex & 0.1756 & 0.083 \\
\hline Age in deciles & 0.061 & 0.012 \\
\hline Follow-up time (high/low) & 0.999 & \\
\hline Diagnosis (TN1 vs TN2) & 0.1334 & 0.215 \\
\hline Diagnosis (any TN vs other) & 0.9953 & \\
\hline Prior surgery for TN & 0.2563 & \\
\hline Any numbness & 0.1416 & 0.114 \\
\hline * Cox regression was used to calculate p values. &
\end{tabular}

Gy. ${ }^{1}$ The primary outcome tool was the BNI pain scale. The investigators divided the 165 patients into a high-dose group and a low-dose group in a dichotomous fashion. No attempt was made to measure pain before the GKRS procedure. At the last follow-up evaluation, the patient was assigned a BNI scale from 1-6, and patients with scores of $1,2,3 \mathrm{~A}$, and $3 \mathrm{~B}$ were considered to have successful outcome. Seventy-one percent of the low dose rate group and $78 \%$ of the high dose rate group achieved successful outcome at last follow-up ( $\mathrm{p}=0.547)$. The authors concluded that there was no statistically significant difference between the low dose rate and high dose rate groups. In another study from Wake Forest, Balamucki et al. ${ }^{2}$ studied 256 patients and classified outcome according to their own scale: excellent, good, fair, and poor. Success was defined as any category except poor, in which poor was defined as "less than 50\% pain relief with or without medications." Again, pain was not measured before intervention. Because the treating physicians used varying doses throughout the treatment period, the investigators attempted to control for the effect of total dose, and based on logistic regression, they concluded that there was no significant correlation between pain relief and dose rate. In addition, using Cox regression, no significant difference was identified in time to pain recurrence based on dose rate. We suspect that one of the reasons these 2 studies have been unable to correlate dose rate with pain outcomes is their use of crude outcome tools in the study of pain.

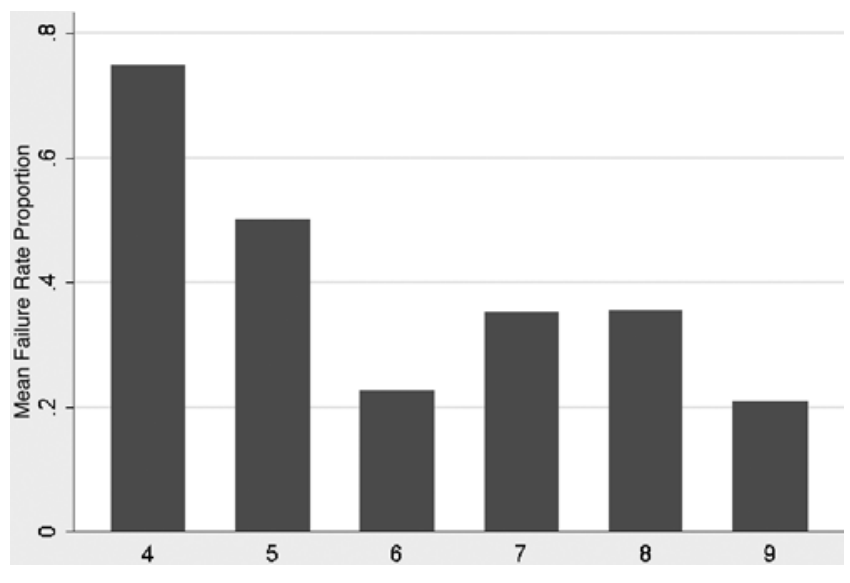

FIG. 4. Bar graph demonstrating the percentage of patients who experienced pain recurrence, according to age deciles (fourth through ninth decade of life). 


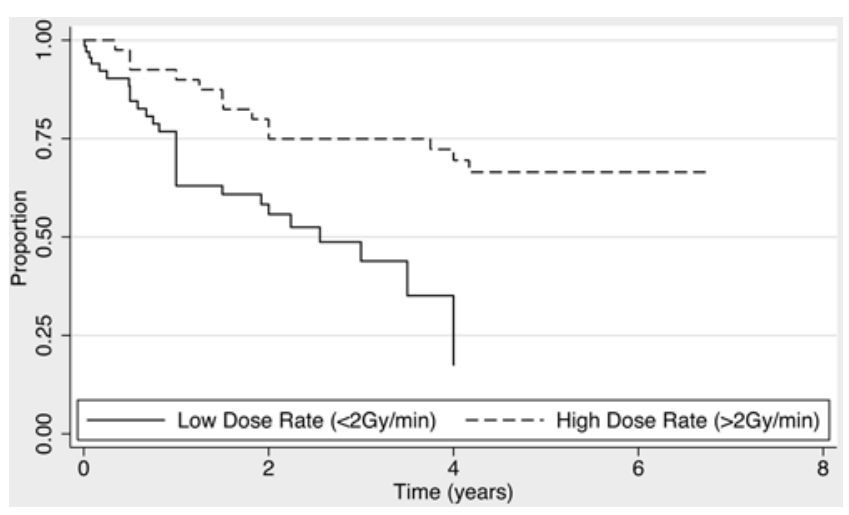

FIG. 5. Kaplan-Meier curves estimating the time to any pain recurrence based on low ( $<2 \mathrm{~Gy} / \mathrm{min}$ ) or high ( $>2 \mathrm{~Gy} / \mathrm{min}$ ) dose rates.

To improve upon the BNI pain grading scale, we chose to create and use the BPI-Facial. This validated outcome tool uses 4 questions targeting pain intensity, 7 questions targeting pain interference with general activities of daily living, and 7 questions targeting pain interference with facial-specific activities of daily living..$^{11}$ The BPI-Facial was administered before and after intervention as well as at the long-term telephone follow-up evaluation. It provides numerical outcome measures that allows for quantitative analysis. In addition, pain scale reports are provided by the patient and not by the treating physician or investigator, thereby limiting reporting bias. We suspect that the lack of clinically significant differences between the high dose rate and low dose rate in the studies by Arai et al. and Balamucki et al. reflects the insensitive outcome tool chosen by the investigators.

The BPI-Facial provides quantitative outcome measures, but to measure durability of clinical outcomes, we chose to employ the standard technique of actuarial Kaplan-Meier analysis using Cox regression. This statistical technique requires a dichotomous outcome (better or not better). A stringent criterion of "any TN pain" versus "none" was chosen for the dichotomous outcome. No account was made as to whether the patient was on medications or not, except to record name, dose and frequency. Using this technique, we performed multivariate Cox regression, and we confirmed that dose rate was the most significant predictor of freedom from pain recurrence.

In our study we could not confirm several published findings that have been shown to be predictors of pain relief. For example, several authors have correlated numb-

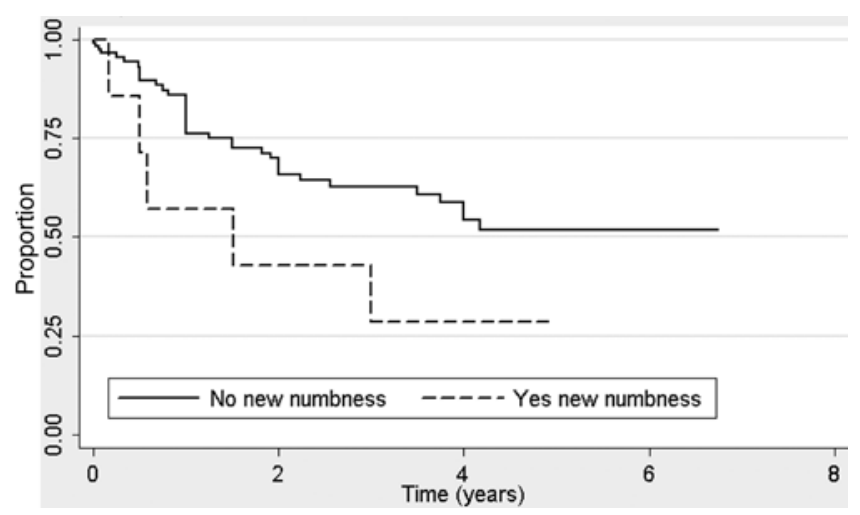

FIG. 6. Kaplan-Meier curves estimating the time to any pain recurrence based on presence or absence of reported facial numbness.

ness with pain relief. ${ }^{14,16,21}$ We did not find an association of pain response with development of new numbness or hypesthesia. In addition, we found that younger age, not older age, ${ }^{7}$ was associated with recurrence of pain, but this may reflect lack of long term follow-up, and we will have to continue to study longer term outcomes to confirm this findings. In addition, we did not review location of the GKRS isocenter as a predictor of outcome. ${ }^{22}$ Despite these limitations and negative findings, we believe that the data we present strongly support the hypothesis that radiosurgical dose rate predicts outcome in patients with TN.

It is known that equivalent doses of absorbed radiation do not necessarily produce equivalent biological effects. The biological effect, or so-called relative biological effectiveness, of a prescribed dose of radiation depends on the following set of factors: 1) dose, 2) fractionation, 3) biological system, 4) quality of radiation (i.e., linear energy transfer), and 5) dose rate. It is provocative to speculate that the dose rate of cobalt- 60 gamma radiation may potentially have an impact on pain outcomes in patients with TN. However, previous studies comparing the dose rate effect of cobalt-60 gamma irradiation of human lymphocytes failed to demonstrate an appreciable difference in the level of radiation effect as measured by chromosomal aberrations when human lymphocytes were exposed to the equivalent dose of radiation (approximately 2 or $4 \mathrm{~Gy}$ ) and delivered over a 2 - or 10 -minute time period. ${ }^{18}$

To our knowledge, our study is the first study to demonstrate an actual effect of dose rate on pain control rates in the treatment of TN and potentially warrant further exploration. However, this study raises intriguing considerations

TABLE 5. Comparison of scores between patients with pain recurrence and no pain recurrence at long-term follow-up*

\begin{tabular}{|c|c|c|c|c|c|c|}
\hline \multirow[b]{2}{*}{ Variable } & \multicolumn{2}{|c|}{ No Recurrence } & \multicolumn{2}{|c|}{ Recurrence } & \multicolumn{2}{|c|}{$p$ Value } \\
\hline & $\begin{array}{l}\text { Absolute } \\
\text { Change }\end{array}$ & $\%$ Change & $\begin{array}{l}\text { Absolute } \\
\text { Change }\end{array}$ & $\%$ Change & $\begin{array}{l}\text { Absolute } \\
\text { Change }\end{array}$ & $\%$ Change \\
\hline Pain intensity-worst & 3.6 & 78 & 1.5 & 59 & 0.0028 & 0.054 \\
\hline Pain intensity-average & 1.9 & 83 & 0.9 & 71 & 0.044 & 0.1849 \\
\hline BPI-General interference items (average) & 1.4 & 86 & 0.6 & 76 & 0.065 & 0.237 \\
\hline BPI-Facial interference items (average) & 1.8 & 85 & 0.9 & 71 & 0.055 & 0.16 \\
\hline$\%$ of patients on AED pain medications* & 26 & & 63 & & 0.0005 & \\
\hline
\end{tabular}

\footnotetext{
* Fisher's exact test.
} 
for treatment of patients with TN. In this study all patients were treated with 80 Gy to the maximum. If the Gamma Knife dose rate has diminished due to cobalt source decay, should the patient be treated with a higher dose such as 85 Gy or 90 Gy to counteract the potentially diminishing biological effect associated with lower dose rate? Because this study is retrospective and as such is only hypothesisgenerating, we believe that changes to clinical practice should only be performed after this finding is validated in a prospective manner.

This study has limitations, as it is a retrospective study with nonblinded, telephone questionnaire follow-up. Indeed, telephone questionnaires can be difficult to administer in patients of advanced age and poor hearing, but we believe our telephone interviewers did everything possible to keep the measures objective. This study was not prospectively designed, although the BPI-Facial was administered in a prospective manner. As such, we do encourage other investigators to use the BPI-Facial as a simple and easy way to measure pain in patients with TN. The BPIFacial is scored by the patient, and thus this limits bias by the treating physician, but obviously this study was not blinded and no independent observer was used to measure outcomes. Because this study was not a controlled study, there is no way to measure the placebo effect in this paper. However, future studies can use the BPI-Facial to measure, in a quantitative manner, the placebo effect of different procedures in patients with TN. Despite these limitations, we find these results to be hypothesis-generating and worthy of discussion.

\section{Conclusions}

A higher dose rate GKRS for TN appears to result in greater magnitude of pain relief at an early follow-up evaluation (1 month). In addition, higher dose rate appears to result in lower rate of recurrence. These results have been generated through use of a validated pain outcome tool that was administered before and after intervention, but these results need to be validated by larger, multiinstitutional studies.

\section{Appendix*}

\section{The Brief Pain Inventory-Facial}

Circle the ONE number that describes how, during the past week, pain has interfered with your:

1. General activity

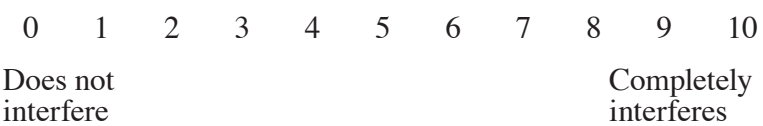

\section{Mood}

$\begin{array}{ccccccccccr}0 & 1 & 2 & 3 & 4 & 5 & 6 & 7 & 8 & 9 & 10 \\ \begin{array}{c}\text { Does not } \\ \text { interfere }\end{array} & & & & & & & \begin{array}{l}\text { Completely } \\ \text { interferes }\end{array}\end{array}$

3. Walking ability

$\begin{array}{ccccccccccc}0 & 1 & 2 & 3 & 4 & 5 & 6 & 7 & 8 & 9 & 10 \\ \text { Does not } \\ \text { interfere }\end{array}$

4. Normal work (includes both work outside the home and housework)

$\begin{array}{ccccccccccc}0 & 1 & 2 & 3 & 4 & 5 & 6 & 7 & 8 & 9 & 10 \\ \begin{array}{l}\text { Does not } \\ \text { interfere }\end{array} & & & & & & & & \begin{array}{l}\text { Completely } \\ \text { interferes }\end{array}\end{array}$

5. Relations with other people

$\begin{array}{ccccccccccc}0 \quad 1 & 2 & 3 & 4 & 5 & 6 & 7 & 8 & 9 \begin{array}{r}10 \\ \text { Completely } \\ \text { interferes }\end{array} \\ \begin{array}{l}\text { Does not } \\ \text { interfere }\end{array} & & & & & & & & & & \\ \begin{array}{l}\text { 6. Sleep } \\ 0 \quad 1\end{array} & 2 & 3 & 4 & 5 & 6 & 7 & 8 & 9 & 10 \\ \begin{array}{l}\text { Does not } \\ \text { interfere }\end{array} & & & & & & & & \begin{array}{l}\text { Completely } \\ \text { interferes }\end{array}\end{array}$

7. Enjoyment of life

$\begin{array}{cccccccccc}0 & 1 & 2 & 3 & 4 & 5 & 6 & 7 & 8 & 9 \\ \begin{array}{l}\text { Does not } \\ \text { interfere }\end{array} & & & & & & & \begin{array}{l}\text { Completely } \\ \text { interferes }\end{array}\end{array}$

8. Eating a meal

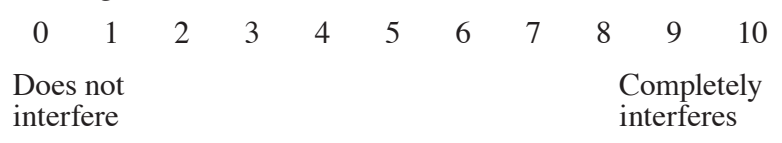

9. Touching your face (including grooming)

$\begin{array}{ccccccccccc}0 & 1 & 2 & 3 & 4 & 5 & 6 & 7 & 8 & 9 & 10 \\ \begin{array}{l}\text { Does not } \\ \text { interfere }\end{array} & & & & & & & \begin{array}{l}\text { Completely } \\ \text { interferes }\end{array}\end{array}$

10. Brushing or flossing your teeth

$\begin{array}{cccccccccc}0 & 1 & 2 & 3 & 4 & 5 & 6 & 7 & 8 & 9 \\ \text { Does not } \\ \text { interfere }\end{array}$

11. Smiling or laughing

$\begin{array}{ccccccccccr}0 & 1 & 2 & 3 & 4 & 5 & 6 & 7 & 8 & 9 & 10 \\ \begin{array}{c}\text { Does not } \\ \text { interfere }\end{array} & & & & & & & \begin{array}{c}\text { Completely } \\ \text { interferes }\end{array}\end{array}$

12. Talking

$\begin{array}{ccccccccccc}0 & 1 & 2 & 3 & 4 & 5 & 6 & 7 & 8 & 9 & 10 \\ \text { Does not } \\ \text { interfere }\end{array}$

13. Opening your mouth widely

$\begin{array}{ccccccccccc}0 & 1 & 2 & 3 & 4 & 5 & 6 & 7 & 8 & 9 & 10 \\ \text { Does not } \\ \text { interfere }\end{array}$

14. Eating hard foods like apples

\begin{tabular}{ccccccccccc}
0 & 1 & 2 & 3 & 4 & 5 & 6 & 7 & 8 & 9 & 10 \\
$\begin{array}{l}\text { Does not } \\
\text { interfere }\end{array}$ & & & & & & & & & $\begin{array}{l}\text { Completely } \\
\text { interferes }\end{array}$ \\
\hline
\end{tabular}


Circle the ONE number that describes your pain at its WORST in the last week.

$\begin{array}{llllllllccc}0 & 1 & 2 & 3 & 4 & 5 & 6 & 7 & 8 & 9 & 10 \\ \text { No } \\ \text { pain }\end{array}$

Circle the ONE number that describes your pain at its LEAST in the last week.

$\begin{array}{lllllllllcc}0 & 1 & 2 & 3 & 4 & 5 & 6 & 7 & 8 & 9 & 10 \\ \text { No } & & & & & & & & \\ \text { pain } & & & & & & & & \\ \text { Pain as bad as an imagine }\end{array}$

Circle the ONE number that describes your pain at its AVERAGE in the last week.

$\begin{array}{llllllllllcc}0 & 1 & 2 & 3 & 4 & 5 & 6 & 7 & 8 & 9 & 10 \\ \text { No } & & & & & & & & \\ \text { pain } & & & & & & & \\ \text { Pain as bad as an imagine }\end{array}$

Circle the ONE number that describes your pain RIGHT NOW.

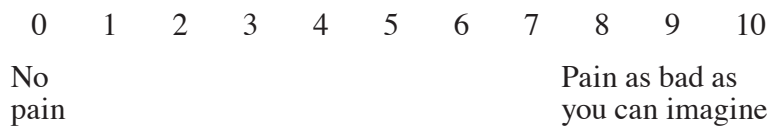
2010.

* Reprinted from Lee JY, et al: J Neurosurg 113:516-523,

\section{References}

1. Arai Y, Kano H, Lunsford LD, Novotny J Jr, Niranjan A, Flickinger JC, et al: Does the Gamma Knife dose rate affect outcomes in radiosurgery for trigeminal neuralgia? J Neurosurg 113 Suppl:168-171, 2010

2. Balamucki CJ, Stieber VW, Ellis TL, Tatter SB, Deguzman AF, McMullen KP, et al: Does dose rate affect efficacy? The outcomes of 256 gamma knife surgery procedures for trigeminal neuralgia and other types of facial pain as they relate to the half-life of cobalt. J Neurosurg 105:730-735, 2006

3. Brisman R: Gamma knife surgery with a dose of 75 to 76.8 Gray for trigeminal neuralgia. J Neurosurg 100:848-854, 2004

4. Burchiel KJ: A new classification for facial pain. Neurosurg 53:1164-1167, 2003

5. Chen HI, Lee JY: The measurement of pain in patients with trigeminal neuralgia. Clin Neurosurg 57:129-133, 2010

6. Flickinger JC, Pollock BE, Kondziolka D, Phuong LK, Foote RL, Stafford SL, et al: Does increased nerve length within the treatment volume improve trigeminal neuralgia radiosurgery? A prospective double-blind, randomized study. Int J Radiat Oncol Biol Phys 51:449-454, 2001

7. Karam SD, Tai A, Wooster M, Rashid A, Chen R, Baig N, et al: Trigeminal neuralgia treatment outcomes following Gamma Knife radiosurgery with a minimum 3-year follow-up. J Radiat Oncol 3:125-130, 2014

8. Kondziolka D, Lunsford LD, Flickinger JC: Stereotactic radiosurgery for the treatment of trigeminal neuralgia. Clin $\mathbf{J}$ Pain 18:42-47, 2002

9. Kondziolka D, Lunsford LD, Flickinger JC, Young RF, Vermeulen S, Duma CM, et al: Stereotactic radiosurgery for trigeminal neuralgia: a multiinstitutional study using the gamma unit. J Neurosurg 84:940-945, 1996

10. Kondziolka D, Zorro O, Lobato-Polo J, Kano H, Flannery TJ, Flickinger JC, et al: Gamma Knife stereotactic radiosurgery for idiopathic trigeminal neuralgia. J Neurosurg 112:758765,2010

11. Lee JY, Chen HI, Urban C, Hojat A, Church E, Xie SX, et al:
Development of and psychometric testing for the Brief Pain Inventory-Facial in patients with facial pain syndromes. J Neurosurg 113:516-523, 2010

12. Lee JY, Moon JG, Kondziolka D, Niranjan A, Flickinger JC, Lunsford LD: Gamma Knife radiosurgery as the primary intervention for trigeminal neuralgia, in Kondziolka D (ed):

Radiosurgery. Basel, Switzerland: Karger, 2006, pp 249-259

13. Lopez BC, Hamlyn PJ, Zakrzewska JM: Stereotactic radiosurgery for primary trigeminal neuralgia: state of the evidence and recommendations for future reports. J Neurol Neurosurg Psychiatry 75:1019-1024, 2004

14. Marshall K, Chan MD, McCoy TP, Aubuchon AC, Bourland JD, McMullen KP, et al: Predictive variables for the successful treatment of trigeminal neuralgia with gamma knife radiosurgery. Neurosurgery 70:566-573, 2012

15. Pollock BE, Ecker RD: A prospective cost-effectiveness study of trigeminal neuralgia surgery. Clin J Pain 21:317322,2005

16. Pollock BE, Phuong LK, Gorman DA, Foote RL, Stafford SL: Stereotactic radiosurgery for idiopathic trigeminal neuralgia. J Neurosurg 97:347-353, 2002

17. Régis J, Metellus P, Hayashi M, Roussel P, Donnet A, BilleTurc F: Prospective controlled trial of gamma knife surgery for essential trigeminal neuralgia. J Neurosurg 104:913924, 2006

18. Scott D, Sharpe HB, Batchelor AL, Evans HJ, Papworth DG: Radiation-induced chromosome damage in human peripheral blood lymphocytes in vitro. II. RBE and dose-rate studies with 60Co gamma- and X-rays. Mutat Res 9:225-237, 1970

19. Smith ZA, Gorgulho AA, Bezrukiy N, McArthur D, Agazaryan N, Selch MT, et al: Dedicated linear accelerator radiosurgery for trigeminal neuralgia: a single-center experience in 179 patients with varied dose prescriptions and treatment plans. Int J Radiat Oncol Biol Phys 81:225-231, 2011

20. Tsai JS, Rivard MJ, Engler MJ, Mignano JE, Wazer DE, Shucart WA: Determination of the $4 \mathrm{~mm}$ Gamma Knife helmet relative output factor using a variety of detectors. Med Phys 30:986-992, 2003

21. Tuleasca C, Carron R, Resseguier N, Donnet A, Roussel P, Gaudart J, et al: Patterns of pain-free response in 497 cases of classic trigeminal neuralgia treated with Gamma Knife surgery and followed up for least 1 year. J Neurosurg 117 Suppl:181-188, 2012

22. Xu Z, Schlesinger D, Moldovan K, Przybylowski C, Sun X, Lee CC, et al: Impact of target location on the response of trigeminal neuralgia to stereotactic radiosurgery. J Neurosurg 120:716-724, 2014

23. Zakrzewska JM, Lopez BC: Quality of reporting in evaluations of surgical treatment of trigeminal neuralgia: recommendations for future reports. Neurosurgery 53:110-122, 2003

\section{Author Contributions}

Conception and design: Lee, Sandhu, Miller. Acquisition of data: Sandhu, Miller. Analysis and interpretation of data: Lee, Dorsey, Alonso-Basanta. Drafting the article: Lee, Sandhu, Dorsey, Alonso-Basanta. Critically revising the article: Lee, Sandhu, Solberg, Dorsey, Alonso-Basanta. Reviewed submitted version of manuscript: Lee, Sandhu, Alonso-Basanta. Approved the final version of the manuscript on behalf of all authors: Lee. Statistical analysis: Lee. Administrative/technical/material support: Sandhu, Miller, Dorsey. Study supervision: Lee.

\section{Correspondence}

John Y. K. Lee, Department of Neurosurgery, University of Pennsylvania, 235 S. Eighth St., Philadelphia, PA 19106. email: leejohn@uphs.upenn.edu. 